\title{
Notas sobre um estudo de fontes: Ribot, Nietzsche e a psicofisiologia francesa do século XIX
}

FREZZATTI JR., Wilson Antonio. Nietzsche e a psicofisiologia francesa do século XIX. São Paulo: Humanitas, 2019.

Antonio Edmilson Paschoal ${ }^{*}$

Um dos principais nomes da pesquisa Nietzsche no Brasil, Wilson Frezzatti oferece à comunidade filosófica nacional uma obra imprescindível para os mais variados exercícios interpretativos sobre o filósofo de Weimar. O livro, denominado Nietzsche e a psicologia francesa do século XIX, vem a lume como parte da coleção "Nietzsche em Perspectiva", coordenada por Vânia Dutra de Azeredo e que já publicou alguns dos textos mais importantes sobre o pensamento de Nietzsche no Brasil. A nova publicação faz corpo também com outros livros já conhecidos do autor, como é o caso do clássico Nietzsche contra Darwin, publicado pela Discurso Editorial em 2001 e que teve uma segunda edição em 2014, pela Loyola; d'A fisiologia de Nietzsche: a superação da dualidade cultural biologia, publicado pela Editora UNIJUÍ, em 2006; sem esquecer a coletânea 120 anos de Para a Genealogia da Moral, publicado também pela Editora UNIJUI, em 2008, organizado com Antonio

\footnotetext{
* Professor do Departamento de Filosofia da Universidade Federal do Paraná (UFPR), Brasil. Correio eletrônico: antonio.paschoal@yahoo.com.br.

ORCID: https://orcid.org/0000-0002-0843-4204
} 
Notas sobre um estudo de fontes: Ribot, Nietzsche e a psicofisiologia francesa do século XIX

Edmilson Paschoal.

Assim como as obras anteriores, Nietzsche e a psicofisiologia francesa do século XIX é o resultado de um meticuloso trabalho de pesquisa de Frezzatti, realizado em grande parte entre os anos de 2009 e 2010 em um estágio de pós-doutorado desenvolvido na França, sob a supervisão do Professor Patrick Wotling, que faz o prefácio da obra. O livro apresenta os resultados de um estudo sobre a correlação entre Friedrich Wilhelm Nietzsche e Théodule-Armand Ribot, tendo em vista a conexão entre filosofia e psicologia e, em especial, o modo como essa conexão se expressa por meio do conceito de "fisio-psicologia". Uma pesquisa que envolve uma temática cara ao autor e que se desdobra, nesse momento, por meio de uma pesquisa de fontes e numa associação com a ideia nietzschiana da vontade de poder. Sendo peculiar no livro, a pesquisa de fontes, que permite trilhar os caminhos da emergência de certos conceitos e ideias em Nietzsche, é colocada em debate, tendo em vista suas possibilidades, mas também seus limites e crenças. $\mathrm{O}$ que faz da obra, também pela disputa que promove sobre metodologias da pesquisa Nietzsche, uma referência imprescindível para a pesquisa sobre o pensamento do filósofo, em especial para quem tem interesse pelo estudo de fontes nesse tipo de pesquisa.

De fato, o livro está voltado para a compreensão da ideia de psicologia que se tem nos escritos de Nietzsche, em um liame indesatável com a ideia de fisiologia. O caminho para essa compreensão, por sua vez, pressupõe uma incursão pela intrincada trama de ligações, desvios e tentações pelos quais se movimentam as pesquisas de fontes no pensamento de Nietzsche. $\mathrm{O}$ grande perigo, a tentação, no caso, consiste na crença exacerbada nas conclusões a que esse tipo de pesquisa conduz e que resumiria como uma influência direta a correlação de Nietzsche com Ribot. Um gesto metodologicamente ilegítimo e que é recusado por Frezzatti - segundo Patrick Wotling, "com grande fineza" - por exemplo, ao colocar em

1 Wotling, 2019, p. 25.

Cad. Nietzsche, Guarulhos/Porto Seguro, v.41, n.3, setembro-dezembro $2020 \mid 253$ 
dúvida a possibilidade do contato direto do filósofo com a obra do psicólogo, preferindo, antes, fazer uma cartografia do modo como a ideia de fisiologia se configura no final do século XIX, num terreno comum a Ribot e Nietzsche.

O mapeamento realizado por Frezzatti permite colocar em relevo, além do contexto comum, também o modo como Nietzsche assimila temas e conceitos do ambiente científico no qual vive e faz questão de conhecer. Nesse ponto, Frezzatti não apenas expõe a ideia de fisiologia em Nietzsche, mas assume essa ideia como pressuposto para explicar a relação de Nietzsche com suas leituras. O que faz associando a ideia de assimilação do processo de digestão, por meio do qual um corpo assimila um alimento, retirando dele os nutrientes de que necessita sem, contudo, assumir a forma do alimento. Nas palavras de Frezzatti, "mais do que receber influências, [Nietzsche] se apropria daquilo que lhe interessa em suas leituras. O filósofo alemão faz a digestão do que lê, transformando-o em elementos de sua filosofia". ${ }^{2}$ Assim, o autor deixa claro que "foi a partir de suas próprias questões" que Nietzsche "foi buscar a ciência e explorou seus conceitos e teorias, modificando-os e absorvendo-os em seu próprio pensamento". ${ }^{3}$ Ou ainda, que "não se trata de afirmar que Nietzsche trouxe dessas teorias científicas suas noções filosóficas". ${ }^{4}$ $\mathrm{O}$ que nos leva a concordar novamente com Wotling em sua ponderação de que, para Frezzatti, "as leituras de Nietzsche são menos influencias que ocasiões de reinterpretações". ${ }^{5}$ De fato, o confronto com a psicologia francesa exerce um papel formador para Nietzsche, tão formador como os alimentos que nutre um corpo saudável. Ele toma o que apetece a ele e deixa de lado o que não interessa, o que não corresponde às suas necessidades filosóficas e convicções. Como um corpo saudável, ele rumina, digere, ou ainda, numa expressão

2 Frezzatti, 2019, p. 212.

3 Frezzatti, 2019, p. 97.

4 Frezzatti, 2019, p. 134.

5 Wotling, 2019, p. 26. 
Notas sobre um estudo de fontes: Ribot, Nietzsche e a psicofisiologia francesa do século XIX

própria a Nietzsche, interpreta, tendo em vista que toda interpretação corresponde a uma assimilação, tendo em vista novas finalidades (GM/GM, II, 12, KSA 5.313-316). Em síntese, ao introduzir um conceito em seus textos, Nietzsche já o transformou. No caso em questão, o material coletado de Ribot em particular e da psicologia francesa do século XIX em geral, adentra na obra de Nietzsche como parte de uma tese formulada por ele e jamais pensada por Ribot: a doutrina da Wille zur Macht.

O tema da entrada de pensadores e ideias em uma filosofia é recorrente na obra de Nietzsche e se apresenta também na recepção de seu pensamento com os mais diferentes contornos. Sobre esse tema, o filósofo se manifesta em várias passagens, atribuindo os mais diferentes significados para o uso feito por ele de personagens e ideias. Um exemplo muito conhecido é a menção ao uso da filosofia kantiana e também da filosofia budista por Schopenhauer, que tinha, segundo Nietzsche, uma única "tarefa", mas que dispunha de inúmeros meios para resolvê-la e para se expressar (SE/ Co. Ext. III, 7, KSA 1.404-411). Outro exemplo, que diz respeito indiretamente ao mesmo texto, é dado com a afirmação do filósofo de que Schopenhauer como Educador corresponderia, mais acertadamente, a Nietzsche como Educador, (EH/EH, As extemporâneas, 3, KSA 6.321), lançando a ideia do uso de diferentes nomes para expor peculiaridades de um si mesmo múltiplo. ${ }^{6}$ Sobre o tema das fontes, tendo em vista a recepção do pensamento de Nietzsche, um dos trabalhos seminais é o de Mazzino Montinari, que correlaciona a obra publicada com os fragmentos póstumos e também com as fontes trabalhadas pelo filósofo no período da sua produção, explorando, a cada momento, a "conexão [do filósofo] com o mundo exterior". 7 Ao certo, contudo, um dos estudos mais exaustivos sobre o tema teve lugar com o inventário da biblioteca de Nietzsche que

6 Conferir, a respeito, por exemplo: Langer, 2005, p. 134ss.

7 Montinari, 1997, p. 78.

Cad. Nietzsche, Guarulhos/Porto Seguro, v.41, n.3, setembro-dezembro $2020 \mid 255$ 
culminou no livro Nietzsches persönliche Bibliothek. ${ }^{8} \mathrm{Um}$ trabalho que não apenas elenca o material que se encontra na biblioteca pessoal de Nietzsche, reconstruída pela irmã, ${ }^{9}$ mas aponta a presença nesse material de registros, anotações e sinais de leitura deixados pelo filósofo. Um trabalho no qual não aparece nenhum livro de Ribot e nem mesmo de algum exemplar da Revue philosophique de la France et de l'Étranger, editada por Ribot.

A ausência de Ribot na biblioteca pessoal de Nietzsche, contudo, não encerra o problema enfrentado por Frezzatti. Ele é bem mais complexo, uma vez que na mesma biblioteca, como salienta o autor do estudo em análise, são encontrados livros de autores que publicavam na Revue ${ }^{10}$ e também de outros autores ligados à psicologia e à fisiologia ${ }^{11}$, além de outros psicólogos franceses como é o caso de Charles Féré ${ }^{12}$ e Leon Dumont, ${ }^{13}$ cujos livros apresentam marcas da leitura de Nietzsche; além do livro de Paul Bourget, Nouveaux essais de psychologie contemporaine, citado por Wilson à página 90 e pelos autores da Nietzsches persönliche Bibliothek nas páginas 148, 149 e 150, com a indicação de vários sinais de leitura. Do mesmo modo como existem registros de obras de pensadores alemães ocupados ao menos indiretamente com o tema, como é o caso de Eduard von Hartmann, de quem aparece a menção a vários livros, nas páginas 283 e 284 da Nietzsches persönliche Bibliothek, com a indicação de inúmeros sinais de leitura.

No sentido de apontar a dimensão e a complexidade da trama na qual adentra uma pesquisa de fontes, Wilson Frezzatti ressalta ainda que há um solo comum entre Nietzsche e Ribot, e também que Ribot, assim como Nietzsche, mobiliza um grande número de teóri-

8 Campioni; D’Iorio; Fornari; Fronterotta; Oruscci, 2002.

9 Cf. Wilamowitz-Moellendorf,, 2008. Observar, em especial, a página 370.

10 Cf. Frezzatti, 2019, p. 76.

11 Cf. Frezzatti, 2019, p. 77.

12 Cf. Campioni; D’Iorio; Fornari; Fronterotta; Oruscci, 2002, p. 225.

13 Cf. Campioni; D’Iorio; Fornari; Fronterotta; Oruscci, 2002, p. 205. 
Notas sobre um estudo de fontes: Ribot, Nietzsche e a psicofisiologia francesa do século XIX

cos para construir o seu próprio trabalho. O que torna essa forma de pesquisa tão produtiva quando difícil de ser levada às suas últimas consequências, pois a experiência mostra o constante aparecimento de leituras não registradas, além de informações indiretas obtidas em livros, artigos ou pessoas que nem sempre são catalogados. Tendo em vista os limites desse tipo de pesquisa, Wilson Frezzatti deixa claro que seu propósito não é leva-la à exaustão, mas servir-se do que nela é indubitável para ampliar o horizonte de compreensão do pensamento do filósofo de Weimar. O que faz por meio daquela cartografia, tão meticulosa quanto reconhecedora de seus limites, e que delineia a complexa rede na qual certas ideias e conceitos circulam e ganham maior ou menor expressão em alguns pontos.

O mapa elaborado por Frezzatti não mostra tanto que Nietzsche "abraça esta ou aquela concepção teórica", mas revela que o filósofo está inserido “em um projeto de transformação dos modos de conhecimento e de entender o mundo, o homem e a cultura", ${ }^{14} \mathrm{e}$ que, para tanto, mantém-se atento à ciência, em especial aos seus movimentos na França no final do século XIX, utilizando elementos dessa ciência, por exemplo, para delinear sua crítica à metafísica. O que permite uma aproximação de algumas de suas teses com a psicologia francesa do século XIX em geral e com Ribot em particular, como é o caso da relação entre a psicologia e a esfera da vida e, por conseguinte, entre a psicologia e a fisiologia; do papel atribuído à doença, não apenas como algo negativo, mas com um importante papel tanto em termos de conhecimento do homem quanto de seus estados de saúde; da reviravolta operada no que concerne à natureza e ao papel do esquecimento, que deixa de ser considerado como uma espécie de incapacidade, para ser tomado como uma condição para a vida e para o seu bom funcionamento.

O trabalho de Frezzatti permite também elucidar lacunas encontradas em pesquisas anteriores, ao mesmo tempo em que abre campos que poderão ser retomados em pesquisas futuras. Um

14 Frezzatti, 2019, p. 95.

Cad. Nietzsche, Guarulhos/Porto Seguro, v.41, n.3, setembro-dezembro $2020 \mid 257$ 
exemplo elucidativo da contribuição de Frezzatti é a aproximação que faz da abordagem do tema do esquecimento, que se tem em Nietzsche, com o pensamento de Ribot. De fato, em algumas pesquisas anteriores essa correlação não era mencionada, como se pode observar, por exemplo, no estudo feito por Werner Stegmaier sobre a Genealogia da moral. ${ }^{15}$ Nesse sentido, vale registrar que Stegmaier acentuou o caráter inovador da acepção de esquecimento de Nietzsche, na medida em que considerou como fonte para o tema apenas a obra de Hermann Ebbingaus, ${ }^{16}$ que toma o esquecimento como um desgaste de impressões assimiladas. Como mostra Frezzatti, porém, o contato do filósofo com as acepções de Ribot sobre o tema constitui um importante material para a compreensão do conceito de esquecimento em Nietzsche. O que é reiterado, por exemplo, por Urs Sommer no seu recente estudo sobre a Genealogia da moral, embora, mesmo nesse caso, a menção a Ribot esteja limitada a uma passagem breve em nota de rodapé. ${ }^{17}$

Outro campo aberto por Frezzatti e que ainda pode ser explorado em pesquisas futuras diz respeito aos estudos sobre a aniquilação da vontade, hipnotização e sonambulismo de Ribot que podem ser evocadas quando se tem em mãos a seção 17 da terceira dissertação da Genealogia da moral de Nietzsche. ${ }^{18}$ De fato, a indicação de Frezzatti nesse ponto é capital para um estudo que considere de forma comparativa os trabalhos de Ribot e os de James Braid que, ao certo, tem também um importante papel na argumentação de Nietzsche, especialmente quando ela faz alusão a um estado correlato ao da hibernação, a um sono profundo, no qual as condições vitais seriam igualmente reduzidas, ficando o corpo num "estado hipnótico". 19

15 Cf. Stegmaier, 1994.

16 Cf. Ebbinghaus, 1885.

17 Cf. Sommer, 2019, p. 249. Sem esquecer ainda que a ideia é anterior também em Nietzsche, aparecendo, por exemplo, na primeira seção da Segunda Consideração Extemporânea.

18 Cf. Frezzatti, 2019, pp. 99-101.

19 Braid, 1882, p. 72. 
Notas sobre um estudo de fontes: Ribot, Nietzsche e a psicofisiologia francesa do século XIX

A indicação de tais possibilidades abertas por Frezzatti permite reafirmar tanto a abrangência dessa modalidade de pesquisa, quanto seus perigos. Por exemplo, de uma crença cega em conclusões apressadas, o que pode levar a colocar em dúvida de forma leviana a autonomia do pensamento de um filósofo, como faz, por exemplo, Erich Hans Lampl, citado por Frezzatti às páginas 214 e 215. De fato, é a autonomia do pensamento de Nietzsche, para quem uma tal influência externa seria inaceitável, que permite a ele manter um inquietante diálogo com o seu tempo, e é a ideia de assimilação que permite a Frezzatti defender a hipótese de que a constituição da noção de vontade de poder de Nietzsche tem lugar no âmbito dessa confrontação as ideias de Ribot e com os estudos sobre a fisiologia.

O livro de Frezzatti termina com um capítulo intitulado "Nietzsche: a superação da metafísica e da própria psicofisiologia científica". Um excerto, ou um balanço final que, ao mesmo tempo, "aproxima e afasta Nietzsche de Ribot". ${ }^{20}$ Nesse capítulo o autor evidencia que apesar de ambos tomarem a fisiologia num movimento de superação, o fato é que Ribot pretende superar a psicologia tradicional, de caráter metafísico, entendida como a ciência da alma, ao passo que Nietzsche pretende superar a moral cristã. Evidencia também as divergências no modo como ambos concebem o termo fisiologia, que denota para Ribot "processos físico-químicos", ao passo que para Nietzsche corresponde à "dinâmica da luta dos impulsos por mais potência". ${ }^{21}$ Aspectos que levam Frezzatti a sugerir que "Nietzsche talvez pensasse que os psicólogos franceses ainda não eram antimetafísicos o suficiente". ${ }^{22}$ Eles ainda acreditavam na verdade, como o faz a ciência em geral, que tem na manutenção da crença na verdade o seu vínculo com a velha metafísica.

20 Frezzatti, 2019, p. 202.

21 Frezzatti, 2019, p. 202.

22 Frezzatti, 2019, p. 211.

Cad. Nietzsche, Guarulhos/Porto Seguro, v.41, n.3, setembro-dezembro $2020 \mid 259$ 


\section{Referências}

BRAID, James. Der Hypnotismus. Berlin: Verlag von Gebruder Paetel, 1882.

CAMPIONI, Giuliano; D’IORIO, Paolo; FORNARI, Maria Cristina; FRONTEROTTA, Francesco; ORUSCCI, Andrea. Nietzsches persönliche Bibliothek. Berlin, New York: Walter de Gruyter, 2002.

EBBINGHAUS, Hermann. Über das Gedächtnis. Leipzig: Verlag von Duncker \& Humblot, 1885.

FREZZATTI Jr., Wilson Antonio. Nietzsche e a psicofisiologia francesa do século XIX. São Paulo: Humanitas, 2019.

LANGER, Daniela. Wie man wird, was man schreibt. Sprache, Subjekt und Autobiographie bei Nietzsche und Barthes. München: Wilhelm Fink Verlag, 2005.

MONTINARI, Mazzino. Ler Nietzsche: O Crepúsculo dos Ídolos. In: Cadernos Nietzsche, São Paulo, v. 3, p. 77-91, 1997.

NIETZSCHE, Friedrich. Schpenhauer como Educador. Trad. Clademir Araldi. São Paulo: Martins Fontes, 2020.

. Genealogia da moral. Trad. Paulo César de Souza. São Paulo: Companhia das Letras, 1998.

. Ecce homo. Como alguém se torna o que é. Trad. Paulo César de Souza. São Paulo: Companhia das Letras, 1995.

SOMMER, Andreas Urs. Kommentar zu Nietzsches Zur Genealogie der Moral. Berlin/Boston: Walter de Gruyter, 2019.

STEGMAIER, Werner. Nietzsches 'Genealogie der Moral'. Darmstadt: Wissenschaftliche Buchgesellschaft, 1994.

WILAMOWITZ-MOELLENDORFF, Erdmann von. O acervo Nietzsche na biblioteca Herzogin Anna Amalia em Weimar. Trad. Antonio Edmilson Paschoal. In: Revista de Filosofia Aurora, Curitiba, v. 20, n. 27, pp. 367-381, jul./dez. 2008.

WOTLING, Patrick. Prefácio: A invenção da psico-fisiologia. In: FREZZATTI Jr., Wilson Antonio. Nietzsche e a psicofisiologia francesa do século XIX. São Paulo: Humanitas, 2019. pp. 13-31.

Enviada: 25/06/2020

Aceita: 30/07/2020 